\title{
Determinants of multidimensional mental wellbeing in the oldest old: a rapid review
}

\author{
Johanna Cresswell-Smith ${ }^{1}$. Francesco Amaddeo ${ }^{2} \cdot$ Valeria Donisi $^{2} \cdot$ Anna K. Forsman $^{3} \cdot$ Jorid Kalseth $^{4}$. \\ Natalia Martin-Maria ${ }^{5,6,7} \cdot$ Marta Miret $^{5,6,7} \cdot$ Kristian Walhbeck $^{1}$
}

Received: 13 August 2018 / Accepted: 15 November 2018 / Published online: 29 November 2018

(c) The Author(s) 2018

\begin{abstract}
Purpose Improved life expectancy imposes new challenges for policy-makers. The growing oldest-old age group (defined as 80 and over) is often characterised by increased support needs. Greater attention to wellbeing in this population group is necessary, and may well require a shift in social policy focus. The current review seeks to explore current research on determinants of mental wellbeing for the oldest old.

Methods An iterative rapid review approach was used to review existing literature in line with four dimensions of mental wellbeing defined by the European Welfare Models and Mental Wellbeing in Final Years of Life (EMMY) study; functional, social, personal and environmental. A specific focus on articles employing multidimensional definitions of mental wellbeing was adopted.

Results Multidimensional indicators reflect the multifaceted and multidirectional dynamics of wellbeing in very old age. Considerable variety in both measures and terminology was found within the literature making precise comparison difficult. The current review takes steps towards comparability by focusing on studies implementing multiple measures of mental wellbeing including evaluative, hedonistic and eudaimonic factors. Clearly defined and multifaceted measures of mental wellbeing are needed to sharpen evidence used in policy development, appraisal and evaluation in light of the considerable diversity of health and functional states experienced in later life.

Conclusions Previous studies appear to line up the four main dimensions of mental wellbeing identified in the EMMY study. Actively improving opportunities for older adults to produce benefits to society can be done via a stronger focus on resources such as mental wellbeing.
\end{abstract}

Keywords Mental wellbeing $\cdot$ Oldest old $\cdot$ Policy development $\cdot$ Determinants

\section{Introduction}

Global projections estimate the share of people aged 80 years or above to triple by 2050, this rate rising to 909 million by 2100 which constitutes a sevenfold increase from 2017

Johanna Cresswell-Smith

johanna.cresswell-smith@thl.fi

1 Mental Health Unit, National Institute for Health and Welfare (THL), PL 30, 00271 Helsinki, Finland

2 Department of Neurosciences, Biomedicine and Movement Sciences, University of Verona, Verona, Italy

3 Faculty of Education and Welfare Studies, Åbo Akademi University, Health Sciences P.B. 311, 65101 Vaasa, Finland

4 Department of Health Research, SINTEF Digital, Trondheim, Norway
[1]. Despite this improved life expectancy being a positive outcome, it also imposes new challenges for policy-makers. Although highly heterogeneous, oldest-old age (defined here as being over 80 years of age) tends to be characterised by increased support needs and morbidity. Ensuring adequate

5 Department of Psychiatry, Universidad Autónoma de Madrid, Madrid, Spain

6 Instituto de Salud Carlos III, Centro de Investigación Biomédica en Red de Salud Mental (CIBERSAM), Madrid, Spain

7 Department of Psychiatry, Hospital Universitario de La Princesa, Instituto de Investigación Sanitaria Princesa (IIS-Princesa), Madrid, Spain 
levels of health and wellbeing in oldest-old age may require additional investment in specific health and social services, but may also be addressed by harnessing existing resources $[2,3]$. A resource-based approach of this kind will require a shift in policy focus.

Policy development has been undergoing considerable change on a global scale in response to increased emphasis on 'beyond Gross Domestic Product (GDP)' approaches [4]. The Organisation for Economic Co-operation and Development (OECD) mission statement "better policies for better lives" highlights not only a good life, but emphasises the need for robust policy to facilitate this [5]. An expanding evidence base on wellbeing indicators supports the use of self-reported measures for informing, monitoring and appraising population wellbeing [6,7]. Wellbeing has been linked with positive outcomes such as good health and life expectancy $[8,9]$. The protective nature of wellbeing on physical health has been studied in different contexts and is particularly important in older age considering the increased risk of illness in later life [10]. Including wellbeing measures in this age group is a step towards more equitable policy but needs to include information from all population groups [11, 12]. Currently, the oldest old remain under-represented in both research and health promotion actions, and are therefore vulnerable to health inequity [13-15].

Definitions of wellbeing are notoriously broad, often including interwoven concepts such as happiness, life satisfaction, positive mental health, quality of life, social capital, mental capital and human functioning [16, 17]. Mental wellbeing and psychological wellbeing are also concepts which may be used interchangeably, and are often discussed in line with resilience, positive psychology and salutogenic perspectives [16, 18]. Mental wellbeing centres around three separate domains; evaluative wellbeing which relates to satisfaction with life, hedonic wellbeing which is linked to positive and negative emotions or affect, and eudaimonic wellbeing with a focus on meaning in life $[12,19]$. More specifically, evaluative wellbeing refers to peoples' thoughts about the quality or goodness of their lives, i.e., their overall satisfaction with their lives [20]. Hedonic wellbeing refers to feelings or moods such as positive and negative affect [21], and eudaimonic wellbeing focuses on judgments about the meaning and purpose of one's life [22]. Although these three domains are associated with one another, they represent distinct aspects of wellbeing [23]. Mental wellbeing has a particularly strong emphasis on the eudaimonic domain highlighting the importance of pursuing meaningful goals, developing and growing as a person, and establishing quality ties [24]. Employing a multidimensional approach which includes all of these domains may produce the most informative results [25].

In order to ameliorate mental wellbeing in the oldestold age group there is a need for a better understanding of its many drivers in later life [26]. Gerontological wellbeing research often highlights the paradoxical observation that older adults, despite their lower objective quality of life, report higher subjective wellbeing than younger age groups [27]. As part of the European Welfare Models and Mental Wellbeing in Final Years of Life (EMMY) project, a recent study by Lara et al. used qualitative methods to decipher what mental wellbeing means to the oldest-old age group. The focus group study found four main dimensions of mental wellbeing to be important namely the functional, social, personal and environmental dimensions [30]. Using a rapid review methodology, the current review builds on this study by exploring recent research along these dimensions. By improving knowledge on the determinants of mental wellbeing in the oldest old we can line up policy with both the resources and needs of this growing population group $[23,28]$.

\section{Methods}

The EMMY project uses interdisciplinary and mixed methods to study the impact of welfare systems on mental wellbeing among the oldest old [29]. A rapid review methodology was used in the current study to explore how previous research reflects the four dimensions of mental wellbeing defined by the EMMY study; the functional social, personal and environmental [30].

Bibliographic searches based on these four dimensions were performed during the months November 2017 to June 2018, covering the last 15 years (2003-2018). The main databases and search engines used were Web of Science (which includes Science Citation Index Expanded; Social Sciences Citation Index; Arts \& Humanities Citation Index and Emerging Sources Citation Index), EBSCOhost (including CINAHL; Academic Search Elite; SocINDEX with Full Text; GreenFILE; Library; Information Science \& Technology Abstracts; AgeLine; PsycInfo), and Google Scholar. Titles and abstracts were scanned by one researcher (JC$\mathrm{S}$ ), if inclusion of the paper was not straightforward; a final decision was made in consultation with a second researcher $(\mathrm{KW})$. More details on the search strategy can be found in Appendix 1.

Age group: The oldest-old age group was defined as 80 years and over. Articles specifically focusing on this age group were prioritised, however articles which encompassed this age group were also included.

Measures of mental wellbeing: With the exception of the Warwick-Edinburgh Mental Wellbeing Scale (WEMWBS), there is a lack of consistent measurement when addressing mental wellbeing [31]. The current review strives for a more multidimensional approach to mental wellbeing by only including literature measuring aspects of evaluative 
wellbeing, hedonic wellbeing, and/or eudaimonic wellbeing. However, considering the lack of research using multifaceted approaches, articles including at least two of these domains were included. Articles focusing on simpler measures of mental wellbeing including only one domain were excluded, as were articles focusing on personality traits or mental health disorders.

A pragmatic approach to qualitative articles was adopted, including articles which broached the topic of mental wellbeing under the particular dimension. Qualitative studies were selected in order to provide depth and meaning and as well as further exploring the relevance of the EMMY study's dimensions [31]. No geographical restrictions were adopted. Only English language articles were included.

Considering the broad nature of wellbeing research, a pragmatic rapid review approach was deemed most appropriate for exploring how the dimensions defined by the EMMY study have been reflected in previous studies. Results were described in line with the four main dimensions defined by the EMMY study, although detailed attention to all subcategories was not possible within the scope of this review [31].

\section{Results}

Title-based searches resulted in a total of 450 articles from the Web of Science database and 602 articles from the EBSCO database. After harmonising articles from both databases and subsequent bibliographic and Google scholar searches, a total of 208 articles were selected for further sifting. This iterative process resulted in a final 15 articles being selected for the review, comprising of 10 quantitative studies and 5 qualitative studies, summarised in Appendix 2.

\section{Functional dimension}

The functional dimension defined by the EMMY study included categories relating to good physical health, activity, energy, restful sleep, and independence [30].

The impact of physical capability on positive mental wellbeing was investigated in a UK cohort study which included five British cohorts participating in the Healthy Ageing across the Life Course (HALCyon) collaboration. The longitudinal study including 3096 participants measured physical capability (grip strength and walking speed, timed get up and go, and chair rise speed) and then 5-10 years later measured mental wellbeing using the multifaceted WEMWBS measure [31]. Participant's ages ranged from 53 to 82 years at onset to 63.6 to 86.6 at time of wellbeing assessment. The study found consistent evidence of (modest) associations between physical capability and positive mental wellbeing, with better performance being associated with higher levels of wellbeing. The study underlines the importance of maintaining physical capability in later life and benefits of using objective and subjective measures as markers of different aspects of ageing [32].

Similarly, Berg et al. investigated mental wellbeing among the oldest-old age group in a longitudinal study including 315 participants aged $80-98$ years from the Swedish population based Origins of Variance in the Old-Old; (OCTO) Twin Study. Evaluative wellbeing was measured using the Life Satisfaction Index-Z inventory [33] in four waves over 6 years, in relation to gender, age, widowhood, socio-economic status, financial satisfaction, perceived quality of social network, self-rated overall health, depressive symptoms, locus of control (LOC) and personality traits. Overall levels of life satisfaction decreased over the 6-year period with individuals who reported better overall health also reporting greater life satisfaction. However, life satisfaction also appeared to be related to other factors such as social network quality, sense of being in control of one's life, and depressive symptoms [34].

Qualitative studies provide important insights into how health, capability and capacity are viewed in later life. Even though health difficulties may be acknowledged to be part of later life, qualitative studies have found a tendency for the oldest old to define their health in relation to their ability to be active and participating, not in relation to symptoms and diseases. Health is defined in relation to what one could expect on the basis of the more or less inevitable symptoms and diseases that come with old age, as reported in a qualitative study by Fänge and Dahlin which was part of the ENABLE-AGE Project. The international study included 40 participants from each of the five participating countries looking for a deeper understanding of the meaning of home, autonomy, health and wellbeing, as well as participation in oldest-old age (between 80 and 89 years of age). Health was defined in terms of being able to manage daily activities and to participate in society. Capacity for activities emerged as key, with participants likely to give up on activities completely if they were considered too demanding. Health and participation was seen to be dependent support and routines in the context of the safety and familiarity of the home [35].

\section{Social dimension}

The broadly defined social dimension highlights the importance of social engagement, social interactions, social networks, and social support as important factors for mental wellbeing [30]. The social dimension is of particular importance considering the heightened risk of social exclusion in oldest-old age [36].

Social network has been found to be associated with aspects of mental wellbeing in the previously mentioned study by Berg et al. Perceived quality of social network was related to greater wellbeing, individuals who were satisfied 
with their social network were also more satisfied with life. Any decreases in life satisfaction in the oldest-old age group were thought likely to relate to the loss of this network. Results also reflected the need to consider gender differences, widowhood for example was found to significantly reduce wellbeing among men [34].

The importance of social networks for the oldest old was also supported by a study by Litwin et al. including 13879 participants, split into age groups of 60-79 and 80 plus from the second wave of the Survey of Health, Ageing and Retirement in Europe (SHARE) survey which measures wellbeing using CASP quality of life scale, and a global measure of life [37]. The study found wellbeing in the oldest-old group to be positively associated with interaction with close persons other than a spouse, within or outside the home, confirming that social networks, still matter in very old age although the composition of social networks may change into oldest-old age [38].

Qualitative research looks at the meaning of social dimensions in later life, a Finnish focus group study by Forsman et al., for example, including 11 participants with an age range of 73-90 looked at mechanisms between social capital and mental wellbeing in older adults including oldest old, particularly in relation to interpersonal relationships. Relationships with the immediate family and life-long friends were highlighted by the participants as being especially important for the mental wellbeing among older adults. Meaningful social activities were found to be essential for maintaining social interaction, enabling interpersonal relationships, as well as fostering a feeling of being needed and enhancing a sense of belonging. Additionally, familiar surroundings of the local neighbourhood and community were found to be highly connected with social capital stressing the need for facilitating local actions and contact with lifelong friends. Loneliness and social isolation were related to functional and social difficulties impeding face-to-face social interaction and participation [39].

\section{Personal dimension}

The personal dimension from the EMMY study includes categories such as autonomy (decision-making), attitude, awareness, being active (keeping busy), intimacy, personal development, relaxation, spirituality and stability [30].

LOC was measured in the aforementioned OCTO Twin Study using the Locus of Control Scale [40] finding individuals with higher internal LOC reporting higher levels of wellbeing on a cross-sectional level [34]. Neubauer et al. investigated the topic of autonomy in oldest-old age line with self-determination theory [41] using the German subsample of the ENABLE-AGE study with 111 participants aged 87-97 years. The study tested whether the universal need for autonomy, competence and relatedness was true also in later life, with results indicating that people are most sensitive towards subtle changes in everyday competence rather than to changes in autonomy in the oldest-old age [42].

Similarly, a longitudinal Swedish study including 681 participants ranging from 78 to 93 years of age looked at how independence affected wellbeing using several measures including Neugarten's Life Satisfaction Index (LSI-A),[43] functional capacity, LOC, health and mental health and other factors previously known to influence mental wellbeing in the oldest-old age group. Life satisfaction remained high for those whose functional capacity remained independent. Life satisfaction assumed to be more likely to be high if the participant found pleasure in everyday-life, saw life as meaningful, and felt most life goals had been achieved [44].

Older adults are more likely to identify themselves as religious, a recent review highlighting positive impacts of spirituality and religiosity in later life [45]. Different dimensions of spirituality contribute to mental wellbeing in later life, measured using the WEMWBS [31] scale in an exploratory cross-sectional study of 279 Belgian participants aged 70-91 years of age. A positive association between spirituality and wellbeing was found, assumed to relate to comfort found via feelings of connectedness with something bigger than oneself, and connectedness with others [46].

Qualitative research allows for personal aspects (which may have stronger eudaimonic nuances to them) to be understood more deeply. Independence, way of life, religion, and personal development were included in the list of 15 higherorder domains reflecting important aspects of wellbeing in later life [47].

The Vitality 90 + study, explored constructions of autonomy among 45 community-dwelling men and women aged 90-91 years. Thematic interviews were used to investigate how they categorised themselves and their autonomy in their everyday lives. Feelings of autonomy were reflected as an ability to make choices and decisions autonomously, despite dependence on other people for physical tasks. Participants tended to define themselves by functional and cognitive ability rather than chronological age, the authors pointing to the need for challenging age-related prerequisites and norms [48].

\section{Environmental dimension}

The EMMY study reported feeling of wellbeing being associated with inspiring sounds, natural landscapes or a nice weather in addition to safety, privacy and freedom [30]. Living conditions can be considered to include a variety of factors including socioeconomic factors. A recent systematic review found lower socio-economic position to be associated with poorer subjective health and wellbeing among older Europeans [49]. 
Living conditions may also reflect the position one has in society. Perceived age discrimination has been found to have negative effects wellbeing measured using the Satisfaction with Life Scale [50]. Results indicated younger age groups (defined as 40-64 year of age) report higher levels of age discrimination in comparison to the older group (defined as 65-93 years of age) although the difference was not statistically significant. The authors did not relate this difference as reflecting less exposure to discrimination, rather explaining it as a process of becoming less sensitive to it due to the prevalent nature of age-related discrimination. Although results pointed more strongly towards negative effects on wellbeing in middle age, it highlighted the need to work on antidiscrimination actions early in order to avoid it being internalised in later life [51].

Qualitative studies address the meaning of environmental factors in later life, often relating to everyday activities. A Canadian qualitative study using interview data from participants aged 65-86 years found green and blue spaces increase motivation to get out of the house to exercise and enjoy the fresh air and surroundings which promoted mental wellbeing, provoking feelings of renewal, restoration, and spiritual connectedness. Green spaces were also considered important spaces for multi-generational social interaction, including planned activities with friends and families, and impromptu social engagements. Thus, being able to experience nature has been linked with physical, mental, and social health in later life [52].

Many references to environmental domains were reported by participants in the aforementioned study by Douma et al. including how functional characteristics of their environment (e.g., proximity of shops) and the perceived characteristics of their living environment (e.g., pleasant or safe) influences wellbeing in later life. Aspects of home-life were emphasised, including the importance of living well, living environment, garden and safety was mentioned by all of the participant groups, in particular by older participants aged 85 years and over [47].

\section{Discussion}

Results from the EMMY study as well as the current review considers mental wellbeing to be a dynamic and multidimensional concept with protective and mediating effects also in later life [30]. Including the notion of mental wellbeing in the oldest-old age group not only shifts focus from deficits and ill-health towards nurturing existing resources, it also allows for a stronger focus on the importance of meaningful, eudaimonic aspects of wellbeing, which can be seen to permeate many of the dimensions highlighted in the EMMY study. Exploring existing knowledge along these dimensions allows us see the interactivity of wellbeing dimensions more clearly, with the potential for support and services to be directed in a more holistic manner.

Health emerged as an important category in the functional dimension, also reflected in previous studies showing higher levels of physical capability and/or health outcomes being related to higher levels of wellbeing. Importantly, improvements in health also resulted in subsequent improvement in wellbeing outcomes. Although there is clear evidence in favour of maintaining physical capability and health in later life, older adults have been seen to adapt and accept limitations as part of the ageing process. Positive thinking and resourcefulness have been identified as mediating challenges, reflected in a tendency towards defining health in relation to abilities, not in terms of symptoms and disease. These findings underline the need to support functional ability despite the existence of ill health, encouraging participation, and defining wellbeing via functionality and ability rather than on impairments.

Different aspects of the social dimension included social engagement, social interactions, social networks, and social support and their impact on mental wellbeing. Along with unbarred access to necessary services, access to social relations has been highlighted as an important aspect in later life, particularly considering that exclusion from both services and social relations has been highlighted as a risk for the oldest-old population. The social network in oldest-old age appears to be particularly important, studies going as far as relating decreases wellbeing to loss of the social network. Close friends and family have been highlighted as particularly important to mental wellbeing, meaning these familiar ties should be particularly protected and prioritised different areas of life for example in living arrangements and daily activities.

The personal dimension makes particular references to eudaimonic themes, which has been described as representing the qualitative aspects of wellbeing, offering potential explanations as to why people are satisfied [25]. The reviewed literature finds independence to be associated with wellbeing and well as finding pleasure and meaning in everyday life and having a sense of one's life goals being achieved. Experiences of purposeful life and personal growth has been reported as contributing to better health outcomes also in other studies [53]. Eudaimonic aspects can be seen to be related to spirituality and religious experiences which have been found to enhance the mental wellbeing in later life. The personal dimension demonstrates the importance of this aspect of wellbeing, and justifies that these opportunities be prioritised into oldest-old age.

The environmental dimension reflects the ethos of environmental gerontology, applying a multidisciplinary focus to the relation between older adults and their surroundings with focus on active participation and engagement of older people in age-friendly environments. An age-friendly environment 
has been described as one which integrates physical and social environments within a model of participatory, collaborative governance,[54] also highlighted in the World Health Organisation (WHO) World Report on Ageing and Health [55]. The environmental dimension emphasises the importance of everyday living conditions and surroundings for mental wellbeing. Recognising barriers specific to the oldest-old population is an important step in creating agefriendly environments. The current review evidences the role of socio-economic status on mental wellbeing in later life, and the significance of environmental factors, particular in terms of living arrangements. External factors may also include effects of discrimination within a society, and should therefore be addressed throughout the life course.

Multidimensional indicators reflect the multifaceted and multidirectional dynamics of wellbeing in very old age [56]. This, however, is complicated by a variety of terms and loosely defined definitions which are often used interchangeably and inconsistently. Although the current review takes steps towards comparability by only including studies implementing multidimensional measures, there was still considerable variety and a lack of consistency in both measures and terminology. Clearly defined, multifaceted measures of mental wellbeing allows for sharper evidence for use in policy development, appraisal and evaluation. Including qualitative evidence gives a deeper understanding of meaningful, eudaimonic aspects of mental wellbeing.

Improved knowledge on the multidimensional nature of mental wellbeing allows easier translation into policy at all levels of governance, across all sectors, throughout the life course. For the oldest-old age group it could mean including more eudaimonic features in policy areas such as health, social support, finance, transport and environmental planning as well as aspects of long term care. This multidimensional approach covers differing needs, reflecting the diversity of health and functional states experienced in later life. It also means mental wellbeing may be further prioritised within the context of healthy ageing, and lends itself well to multidimensional tools such as the Mental Wellbeing Impact Assessment (MWIA) Toolkit for wellbeing in providing evidence-based frameworks for assessing and improving policy programmes and services [57].

\section{Strengths and limitations}

The current rapid review takes a novel approach in terms of exploring how existing literature lines up with the dimensions of mental wellbeing in the oldest old, as defined in the EMMY study [31]. Although a step towards a clearer understanding of the building blocks of mental wellbeing in later life, the current study does have several limitations.
Wellbeing research is marred by complications stemming from inconsistencies in terminology and measures [17]. Employing a fluid and flexible rapid review methodology allowed for an iterative process and broader inclusion possibilities, but also increased the risk reporting bias by inadvertently omitting relevant studies. Additionally, the limited number of researchers involved in the search and selection process facilitated the rapid review approach, but also increased the risk of reporting bias. By framing our approach using dimensions defined by The EMMY study, focus was placed on areas with potential relevance for policy development rather than exploring exact nuances of mental wellbeing.

Research specifically on mental wellbeing of the oldestold age group appears to be underrepresented in relation to the ongoing demographic transition. Although a heterogeneous population group, the oldest-old age group can be considered to have certain distinct features in terms of health and wellbeing, and could therefore benefit from a stronger evidence base. The current review made an attempt at including articles focusing specifically on the oldest-old age group, although variations in age ranges and the paucity of wellbeing research specifically on the oldest-old age group meant a more pragmatic approach was needed. This pragmatic approach meaning only 6 out of the 15 included studies focused exclusively on the oldest-old age group, with the remaining studies included the oldest-old age group within a larger age-range. Thus, the oldest-old age group was represented in all of the included articles, although a stricter focus on the oldest-old age category would have been preferred.

A further strength of the current study is its contribution towards increased knowledge on mental wellbeing as a resource later in life. Areas for future study include a more detailed overview of how public policy could include determinants of mental wellbeing for the oldest-old age group, providing groundwork for best practice and impact assessment approaches.

\section{Conclusion}

Older adults have poignantly been described as the "world's only increasing natural resource in developed countries", highlighting the need for investing in the wellbeing in later life [58]. Actively improving opportunities for older adults to produce benefits to society can be done via a stronger focus on resources such as mental wellbeing. In order for this to be possible, a deeper understanding of what constitutes mental wellbeing in the older population groups has been necessary.

Including stronger focus of the importance of meaningful, eudaimonic aspects aspect of wellbeing can be an important stepping stone towards building inclusive, age-friendly 
environments. Including mental wellbeing in policy development, assessment and evaluation may require multidimensional tools and evidence-based frameworks. Actively developing policy actions which improve the mental wellbeing of the oldest old is a step towards harnessing existing resources and ameliorating positive outcomes in response to the ongoing demographic transition.

Acknowledgements Open access funding provided by National Institute for Health and Welfare (THL).

Funding The support of the Joint Programming Initiative More Years Better Lives is gratefully acknowledged.

\section{Compliance with ethical standards}

Conflict of interest On behalf of all authors, the corresponding author states that there is no conflict of interest.

Open Access This article is distributed under the terms of the Creative Commons Attribution 4.0 International License (http://creativeco mmons.org/licenses/by/4.0/), which permits unrestricted use, distribution, and reproduction in any medium, provided you give appropriate credit to the original author(s) and the source, provide a link to the Creative Commons license, and indicate if changes were made.

\section{Appendix 1: Summary of search terms}

A series of iterative searches were performed using search terms which covering dimensions defined by the EMMY study [30]. Title or abstract searches were performed in three fields including various combinations of the following terms and their synonyms.

\section{Functional dimension}

Mental wellbeing, OR psychological wellbeing, OR emotional wellbeing, OR well being

\section{AND}

Oldest old, OR old*

AND

Health or functional, OR physical, OR capability, OR capacity

\section{Social dimension}

Mental wellbeing, OR psychological wellbeing, OR emotional wellbeing, OR well being

AND

Oldest old, OR old*

AND

Social, OR social networks, OR social interactions, OR social support, OR social engagement, OR loneliness, OR social isolation, OR social exclusion

\section{Personal dimension}

Mental wellbeing, OR psychological wellbeing, OR emotional wellbeing, OR well being

AND

Oldest old, OR old*

AND

Autonomy, OR decision making, OR attitude, awareness, OR intimacy, OR personal development, OR relaxation, OR spirituality, OR stability.

\section{External dimension}

Mental wellbeing, OR psychological wellbeing, OR emotional wellbeing, OR well being

AND

Oldest old, OR old*

AND

Environment, OR living conditions, OR surroundings, OR socio-economic 


\section{Appendix 2: Summary of included studies}

\begin{tabular}{|c|c|c|c|c|c|c|c|c|}
\hline Authors & $\begin{array}{l}\text { Research } \\
\text { design }\end{array}$ & Dimension & Year & $\begin{array}{l}\text { Type of } \\
\text { study }\end{array}$ & $N$ & Age & $\begin{array}{l}\text { Mental wellbe- } \\
\text { ing measures }\end{array}$ & Other measures \\
\hline Cooper et al. [32] & Quantitative & Functional & 2014 & Longitudinal & 3096 & $\begin{array}{c}53-82 \text { years and } \\
63.6-86.6\end{array}$ & WEMWBS & $\begin{array}{c}\text { Four physical } \\
\text { capability } \\
\text { measures }\end{array}$ \\
\hline Berg et al. [34] & Quantitative & Functional & 2006 & Longitudinal & 315 & $80-98$ & $\begin{array}{l}\text { Life Satisfac- } \\
\text { tion Index-Z }\end{array}$ & $\begin{array}{l}\text { Demograph- } \\
\text { ics, health, } \\
\text { Activities of } \\
\text { Daily Liv- } \\
\text { ing (ADL), } \\
\text { cognitive, } \\
\text { depression, } \\
\text { LOC, social } \\
\text { network }\end{array}$ \\
\hline $\begin{array}{l}\text { Fänge and Dahlin } \\
\text { [35] }\end{array}$ & Qualitative & Functional & 2009 & $\begin{array}{l}\text { Cross-sec- } \\
\text { tional }\end{array}$ & 40 & $80-89$ & Interview & \\
\hline Berg et al. [34] & Quantitative & Social & 2006 & Longitudinal & 315 & $80-98$ & $\begin{array}{l}\text { Life Satisfac- } \\
\text { tion Index-Z }\end{array}$ & $\begin{array}{l}\text { Demographics, } \\
\text { health, ADL, } \\
\text { cognitive, } \\
\text { depression, } \\
\text { LOC, social } \\
\text { network }\end{array}$ \\
\hline $\begin{array}{l}\text { Litwin and } \\
\text { Stoeckel [38] }\end{array}$ & Quantitative & Social & 2013 & Longitudinal & 13,879 & $\begin{array}{l}60-79 \text { and } 80 \\
\text { plus }\end{array}$ & $\begin{array}{l}\text { CASP-12 } \\
\text { quality of life } \\
\text { scale, and } \\
\text { global meas- } \\
\text { ure of life } \\
\text { satisfaction }\end{array}$ & $\begin{array}{l}\text { Socio-economic } \\
\text { indicators, } \\
\text { ADL }\end{array}$ \\
\hline $\begin{array}{l}\text { Forsman et al. } \\
\text { [40] }\end{array}$ & Qualitative & Social & 2013 & $\begin{array}{l}\text { Cross-sec- } \\
\text { tional }\end{array}$ & 11 & $73-90$ & $\begin{array}{l}\text { Focus group } \\
\text { interviews } \\
\text { and open- } \\
\text { ended ques- } \\
\text { tioning }\end{array}$ & \\
\hline Berg et al. [34] & Quantitative & Personal & 2006 & Longitudinal & 315 & $80-98$ & $\begin{array}{l}\text { Life Satisfac- } \\
\text { tion Index-Z }\end{array}$ & $\begin{array}{l}\text { Demographics, } \\
\text { health, ADL, } \\
\text { cognitive, } \\
\text { depression, } \\
\text { LOC, social } \\
\text { network }\end{array}$ \\
\hline $\begin{array}{l}\text { Nebayer et al. } \\
\text { [43] }\end{array}$ & Quantitative & Personal & 2017 & Longitudinal & 111 & $87-97$ & $\begin{array}{l}\text { The Satisfac- } \\
\text { tion with } \\
\text { Life Scale } \\
\text { Positive and } \\
\text { Negative } \\
\text { Affect } \\
\text { Schedule }\end{array}$ & $\begin{array}{l}\text { Need fulfil- } \\
\text { ment using } \\
\text { the subscales } \\
\text { "autonomy" } \\
\text { and "envi- } \\
\text { ronmental } \\
\text { mastery" } \\
\text { Cognitive } \\
\text { functioning, } \\
\text { perceived } \\
\text { health }\end{array}$ \\
\hline Enkvist et al. [44] & Quantitative & Personal & 2012 & Longitudinal & 681 & $78-93$ & $\begin{array}{r}\text { Neugarten's } \\
\text { QoL Scale }\end{array}$ & $\begin{array}{l}\text { Subjective } \\
\text { health, } \\
\text { ADL, Mini } \\
\text { Mental State } \\
\text { Examination, } \\
\text { Psychiatric } \\
\text { Rating Scale, } \\
\text { health, LOC } \\
\text { scale }\end{array}$ \\
\hline
\end{tabular}




\begin{tabular}{|c|c|c|c|c|c|c|c|c|}
\hline Authors & $\begin{array}{l}\text { Research } \\
\text { design }\end{array}$ & Dimension & Year & $\begin{array}{l}\text { Type of } \\
\text { study }\end{array}$ & $N$ & Age & $\begin{array}{l}\text { Mental wellbe- } \\
\text { ing measures }\end{array}$ & Other measures \\
\hline $\begin{array}{l}\text { Thauvoye et al. } \\
\text { [46] }\end{array}$ & Quantitative & Personal & 2017 & $\begin{array}{l}\text { Cross-sec- } \\
\text { tional }\end{array}$ & 279 & $70-91$ & WEMWBS & $\begin{array}{l}\text { Socio-Demo- } \\
\text { graphic, } \\
\text { Spirituality }\end{array}$ \\
\hline Douma et al. [47] & Qualitative & Personal & 2017 & $\begin{array}{l}\text { Cross-sec- } \\
\text { tional }\end{array}$ & 66 & $65-83$ & Word clouds & \\
\hline $\begin{array}{l}\text { Pirhonen et al. } \\
\text { [48] }\end{array}$ & Qualitative & Personal & 2016 & $\begin{array}{l}\text { Cross-sec- } \\
\text { tional }\end{array}$ & 45 & $90-91$ & $\begin{array}{l}\text { Life-story } \\
\text { interviews }\end{array}$ & \\
\hline Read et al. [49] & Review & $\begin{array}{l}\text { Environmen- } \\
\text { tal }\end{array}$ & 2015 & Review & & & & \\
\hline Avidor et al. [51] & Quantitative & $\begin{array}{l}\text { Environmen- } \\
\text { tal }\end{array}$ & 2016 & Longitudinal & 1534 & 40-64 and 65-93 & $\begin{array}{l}\text { Satisfac- } \\
\text { tion with } \\
\text { Life Scale, } \\
\text { Positive } \\
\text { and Nega- } \\
\text { tive Affect } \\
\text { Schedule }\end{array}$ & $\begin{array}{l}\text { Perceived } \\
\text { age dis- } \\
\text { crimination, } \\
\text { Subjective life } \\
\text { expectancy, } \\
\text { demographic } \\
\text { information }\end{array}$ \\
\hline Finlay et al. [52] & Qualitative & $\begin{array}{l}\text { Environmen- } \\
\text { tal }\end{array}$ & 2015 & $\begin{array}{l}\text { Cross-sec- } \\
\text { tional }\end{array}$ & 141 & $65-86$ & $\begin{array}{l}\text { In-depth } \\
\text { qualitative } \\
\text { interviews }\end{array}$ & \\
\hline
\end{tabular}

\section{References}

1. United Nations (2017) Department of Economic and Social Affairs, Population Division. World Population Prospects: The 2017 Revision, Key Findings and Advance Tables, Working Paper No. ESA/P/WP/248

2. Pickard L (2015) 'A growing care gap? The supply of unpaid care for older people by their adult children in England to 2032'. Ageing Soc 35(1):96-123

3. Briggs AM, Cross MJ, Hoy DG, Sànchez-Riera L, Blyth FM, Woolf AD, March L (2016) Musculoskeletal health conditions represent a global threat to healthy aging: a report for the 2015 World Health Organization world report on ageing and health. Gerontol 56(2):S243-S255

4. OECD (2017) How's life? 2017: measuring well-being. OECD, Paris. https://doi.org/10.1787/how_life-2017-en

5. OECD (2013) OECD Guidelines on measuring subjective wellbeing. OECD, Paris. https://doi.org/10.1787/9789264191655-en

6. Diener E (ed) (2009) Assessing well-being: the collected works of Ed Diener, social indicators research series 39. Springer, Dordrecht

7. Dolan P, Peasgood T, White M (2008) Do we really know what makes us happy? A review of the economic literature on the factors associated with subjective well-being. J Econ Psychol 29:94-122

8. Huppert F (2009) Psychological well-being: evidence regarding its causes and consequences. Appl Psychol Health Well Being 1(2):137-164

9. Chida Y, Steptoe A (2008) Positive psychological well-being and mortality: a quantitative review of prospective observational studies. Psychosom Med 70(7):741-756

10. Diener E, Chan MY (2011) Happy people live longer: subjective well-being contributes to health and longevity. Appl Psychol Health Well Being 3:1-43

11. Stiglitz J (2009) Report by the commission on the measurement of economic performance and social progress. http://www.stigl itz-sen-fitoussi.fr. Accessed 1 Mar 2018
12. Dolan P, Metcalfe R (2012) Measuring subjective wellbeing: recommendations on measures for use by national governments. J Soc Policy 41:409-427

13. Miret M, Cabello M, Marchena C, Mellor-Marsá B, Caballero FF, Obradors-Tarragó C, Haro JM, Ayuso-Mateos JL (2015) The state of the art on European well-being research within the area of mental health. Int J Clin Health Psychol 2:171-179

14. Liljas AEM, Walters K, Jovicic A, Iliffe S, Manthorpe J, Goodman C, Kharicha K (2017) Strategies to improve engagement of 'hard to reach' older people in research on health promotion: a systematic review. BMC Public Health 17:349

15. McMurdo ME, Roberts H, Parker S, Wyatt N, May H, Goodman $C$ et al (2011) Improving recruitment of older people to research through good practice. Age Ageing 40(6):659-665

16. Salvador-Carulla L, Lucas R, Ayuso-Mateos JL, Miret M (2014) Use of the terms "wellbeing" and "quality of life" in health sciences: a conceptual framework. Eur J Psychia 28(1):50-65

17. Linton M-J, Dieppe P, Medina-Lara A (2016) Review of 99 self-report measures for assessing wellbeing in adults: exploring dimensions of well-being and developments over time. BMJ Open 6:e010641. https://doi.org/10.1136/bmjopen-2015-010641

18. Bowling A (2013) The definition and measurement of wellbeing and quality of life in mental health promotion and outcomes. In: Mehta N (ed) Annual report of the chief medical officer: public mental health priorities. Making mental health services more effective and accessible. Department of Health, London, pp 287-297

19. Diener E (2006) Guidelines for national indicators of subjective well-being and ill-being. J Happiness Stud 7(4):397-404

20. Cantril H (1965) The pattern of human concerns. Rutgers University Press, New Brunswick

21. Kahneman D, Krueger AB, Schkade DA, Schwarz N, Stone AA (2004) A survey method for characterizing daily life experience: the day reconstruction method. Science 306(5702):1776-1780

22. Ryff CD, Singer BH, Dienberg Love G (2004) Positive health: connecting well-being with biology. Philos Trans R Soc Lond B Biol Sci 359(1449):1383-1394

23. Steptoe A, Deaton A, Stone AA (2015) Psychological wellbeing, health and ageing. Lancet 385(9968):640-648 
24. Chen FF, Jing Y, Hayes A, Lee JM (2013) Two concepts or two approaches? A bifactor analysis of psychological and subjective well-being. J Happiness Stud 14(3):1033-1068

25. Vanhoutte B (2014) The multidimensional structure of subjective well-being in later life. J Popul Ageing 7(1):1-20

26. Huppert FA (2009) Psychological well-being: evidence regarding its causes and consequences. Appl Psychol Health Well Being $1: 137-164$

27. Hansen T, Slagsvold B (2012) The age and subjective well-being paradox revisited: a multidimensional perspective. Norsk Epidemiol 22:187-195

28. Steptoe A, Demakakos P, de Oliveira C (2012) The psychological well-being, health and functioning of older people in England. In: Banks J, Nazroo J, Steptoe A (eds) The dynamics of ageing: evidence from the English longitudinal study of ageing 2002-2010 (Wave 5). Institute for Fiscal Studies, London, pp 98-182

29. The European Welfare Models and Mental wellbeing in final years of life (EMMY) http://www.emmyproject.org. Accessed 10 Mar 2018

30. Lara E, Martín-María N, Forsman A, Cresswell-Smith J, Donisi V, Ådnanes M, Kaasbøll J, Melby L, Nordmyr J, Nyholm L, Rabbi L, Amaddeo F, Miret M (2018) Understanding the multi-dimensional mental well-being in late life: evidence from the perspective of the oldest old population. J Happiness Stud (submitted)

31. Tennant R, Hiller L, Fishwick R, Platt S, Joseph S, Weich S, Parkinson J, Secker J, Stewart-Brown S (2007) The Warwick-Edinburgh Mental Well-being Scale (WEMWBS): development and UK validation. Health Qual Life Outcomes 5:63

32. Cooper R, Stafford M, Hardy R et al (2014) Physical capability and subsequent positive mental wellbeing in older people: findings from five Halcyon cohorts. Age 36:445

33. Wood V, Wylie ML, Sheafor B (1969) An analysis of a short self-report measure of life satisfaction: correlation with rater judgments. J Gerontol 24(4):465-469

34. Berg AI, Hassing LB, Mcclearn GE, Johnsson B (2006) What matters for life satisfaction in the oldest-old? Aging Ment Health 10(3):257-264

35. Fänge A, Dahlin Ivanoff S (2009) The home is the hub of health in very old age: findings from the ENABLE-AGE Project. Arch Gerontol Geriatr 48(3):340-345

36. Key W, Culliney M (2018) The oldest old and the risk of social exclusion. Soc Policy Soc 17(1):47-63

37. Hyde M, Wiggins RD, Higgs P, Blane DB (2003) A measure of quality of life in early old age: the theory, development and properties of a needs satisfaction model (CASP-19). Aging Ment Health 7(3):186-194

38. Litwin H, Stoeckel K (2013) Social networks and subjective wellbeing among older Europeans: does age make a difference? Ageing Soc 33(7):1263-1281

39. Forsman A, Herberts C, Nyqvist F, Wahlbeck K, Schierenbeck I (2013) Understanding the role of social capital for mental wellbeing among older adults. Ageing Soc 33(5):804-825

40. Rotter JB (1966) Generalized expectancies for internal versus external control of reinforcement. Psychol Monogr 80(1):1-28

41. Deci EL, Ryan RM (1985) Intrinsic motivation and self-determination in human behavior. Plenum, New York
42. Nebayer AB, Schilling OK, Wahl HW (2017) What do we need at the end of life? Competence, but not autonomy, predicts intraindividual fluctuations in subjective well-being in very old age. $\mathrm{J}$ Gerontol 72(3):425-435

43. Neugarten BL, Havighurst RJ, Tobin SS (1961) The measurement of life satisfaction. J Gerontol 16:134-143

44. Enkvist Å, Ekström H, Elmståhl S (2012) What factors affect life satisfaction (LS) among the oldest-old? Arch Gerontol Geriatr 54(1):140-145

45. Zimmer Z, Jagger C, Chiu CT, Ofstedal MB, Rojo F, Saito Y (2016) Spirituality, religiosity, aging and health in global perspective: a review. SSM Popul Health 2:373-381

46. Thauvoye E, Vanhooren S, Vandenhoeck A, Dezutter J (2017) Spirituality and well-being in old age: exploring the dimensions of spirituality in relation to late-life functioning. J Relig Health. https://doi.org/10.1007/s10943-017-0515-9

47. Douma L, Steverink N, Hutter I, Meijering L (2017) Exploring subjective well-being in older age by using participant-generated word clouds. Gerontol 57(2):229-239

48. Pirhonen J, Ojala H, Lumme-Sandt K, Pietilä I (2016) 'Old but not that old': Finnish community-dwelling people aged 90 negotiating their autonomy. Ageing Soc 36(8):1625-1644

49. Read S, Grundy E, Foverskov E (2016) Socio-economic position and subjective health and well-being among older people in Europe: a systematic narrative review. Aging Mental Health 20(5):529-542

50. Pavot W, Diener E (1993) Review of the satisfaction with life scale. Psychol Assess 5:164172

51. Avidor S, Ayalon L, Palgi Y, Bodner E (2017) Longitudinal associations between perceived age discrimination and subjective well-being: variations by age and subjective life expectancy. Aging Ment Health 21(7):761-765

52. Finlay J, Franke T, McKay H, Sims-Gould J (2015) Therapeutic landscapes and wellbeing in later life: impacts of blue and green spaces for older adults. Health Place 34:97-106

53. Zaslavsky O, Rillamas-Sun E, Woods NF, Cochrane BB, Stefanick ML, Tindle $\mathrm{H}$ et al (2014) Association of the selected dimensions of eudaimonic well-being with healthy survival to 85 years of age in older women. Int Psychogeriatr 26(12):2081-2091

54. Lui C, Everingham J, Warburton J, Cuthill M, Bartlett H (2009) What makes a community age-friendly: a review of international literature. Aust J Ageing 28(3):116-121

55. Beard J, Officer A, Cassels A (2015) World report on ageing and health, World Health Organization, Geneva. http://www.who.int/ ageing/publications/world-report-2015/en/. Accessed 20 May 2018

56. Wettstein M, Schilling O, Reidick O, Wahl H (2015) Four-year stability, change, and multidirectionality of well-being in very-old age. Psychol Aging (3):500

57. Cooke A, Friedli L, Coggins T, Edmonds N, Michaelson J, O'Hara K, Snowden L, Stansfield J, Steuer N, Scott-Samuel A (2011) MWIA: a toolkit for wellbeing, 3rd edn. National MWIA Collaborative, London

58. Fried LP (2016) Investing in health to create a third demographic dividend. Gerontol 56(2):167-177 